\title{
Barium aspiration through a tracheo-oesophageal fistula caused by percutaneous tracheostomy
}

\author{
Moayad Majed Alqurashi, ${ }^{1}$ Majed Ayed Alshammari, ${ }^{1}$ Hamdan Al-Jahdali ${ }^{2,3}$
}

'Department of Internal Medicine, King Abdulaziz Medical City, Riyadh, Saudi Arabia

${ }^{2}$ Division of Pulmonary Services, Department of Internal Medicine, King Abdulaziz Medical City, Riyadh, Saudi Arabia

${ }^{3}$ College of Medicine, King Saud bin Abdulaziz University for Health Sciences, Riyadh, Saudi Arabia

\section{Correspondence to} Dr Moayad Majed Alqurashi, moayad.alqurashi@hotmail.com

Accepted 26 June 2017
CrossMark

To cite: Alqurashi MM, Alshammari MA, Al-Jahdali $\mathrm{H}$. BMJ Case Rep Published Online First: [please include Day Month Year]. doi:10.1136/bcr-2017220486

\section{DESCRIPTION}

A healthy 43-year-old gravida 14, para $12+1$ woman, developed Sheehan syndrome followed by disseminated intravascular coagulopathy and sepsis post-Caesarean section. Her postoperative course was further complicated by a hospital-acquired pneumonia for which she required endotracheal intubation and mechanical ventilation. Enteral feeding and medications were administered via a nasogastric tube (NGT). After three failed attempts at extubation, a tracheostomy was inserted percutaneously. Over the next 2 weeks, she improved and was successfully weaned off ventilatory support. She was transferred to a medical ward with the tracheostomy in situ with minimum oxygen requirement.

Her rehabilitation progressed slowly while the NGT was kept in situ in view of recurrent aspiration with oral intake. A barium study was performed via the NGT after she developed severe vomiting and CT of the abdomen was reported as normal. This demonstrated mild gastritis and delayed gastric emptying due to ileus. No immediate complications were apparent during the barium study.

A few hours after the barium study, the patient vomited and reported mild breathlessness. Although she did develop a slight tachypnoea, she did not desaturate and there was no increase in oxygen requirement. Rather unexpectedly, a chest

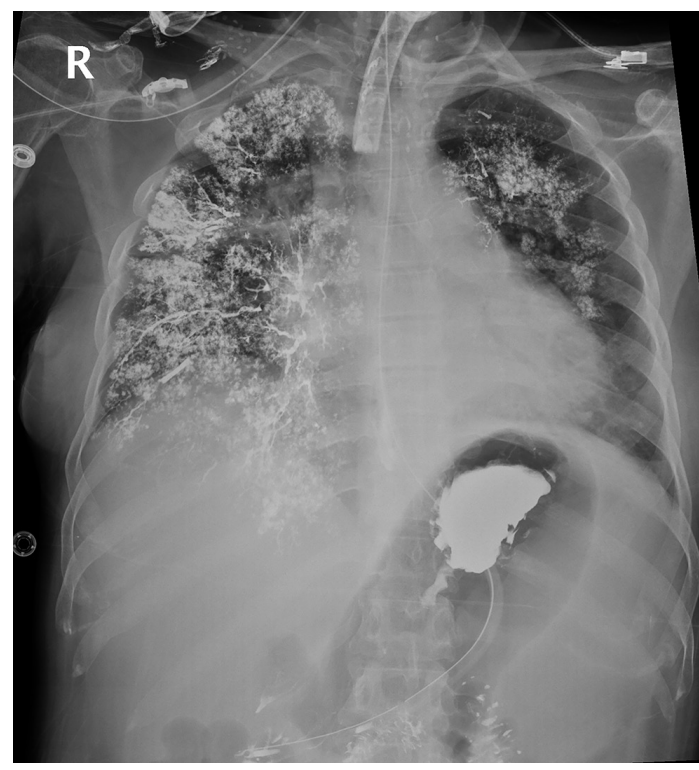

Figure 1 Chest X-ray showing massive bilateral aspiration of barium. The right lung was affected more than the left.

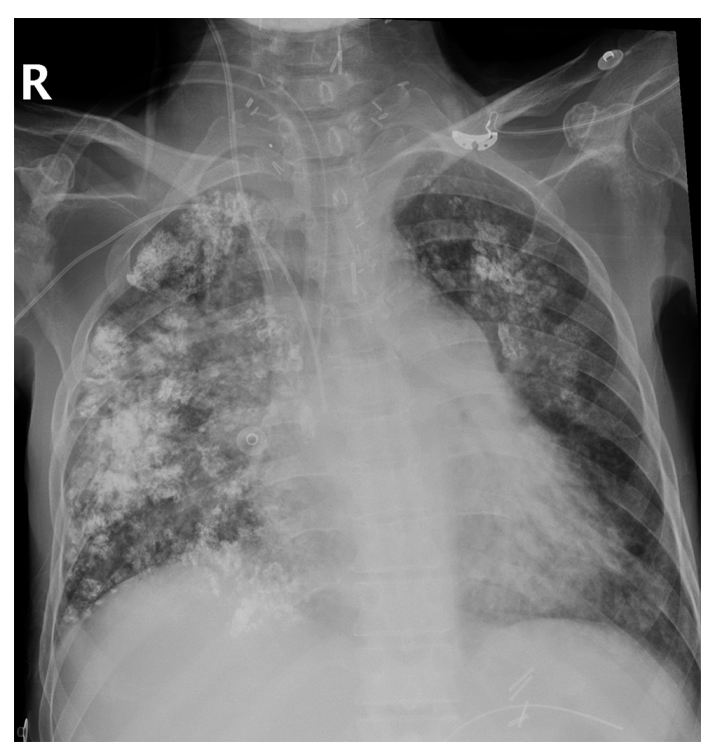

Figure 2 A 5-month follow-up chest X-ray showing persistent bilateral aspiration of barium with similar distribution compared with the initial chest $\mathrm{X}$-ray.

X-ray revealed massive bilateral aspiration of barium that had affected the right lung more than the left (figure 1). The extent of the radiological abnormalities was significantly out of proportion to her mild symptoms and signs.

Radio-opacities due to aspirated barium usually persist for many years due to slow clearance. ${ }^{1}$ Indeed, a chest X-ray performed 5 months after aspiration of barium (figure 2) still showed residual opacities.

\section{Learning points}

- Although barium aspiration can be fatal, as demonstrated by the present case the initial symptoms, signs and effects on respiratory function may be mild.

- Administration of feed or medications via nasogastric tube does not prevent aspiration via a tracheo-oesophageal fistula.

- Tracheo-oesophageal fistula is an uncommon complication of percutaneous tracheostomy, which can coexist with oropharyngeal aspiration and may be masked by the presence of a nasogastric tube.

- After tracheostomy, a high index of suspicion and a low threshold for performing bronchoscopy are required to detect tracheooesophageal fistula. 
After aspiration of the barium, NGT feed was intermittently suctioned via the tracheostomy tube, so bronchoscopy was performed. This revealed a $2 \mathrm{~cm} \times 4 \mathrm{~cm}$ tracheo-oesophageal fistula $10 \mathrm{~cm}$ from the carina on the posterior wall of the trachea. This was repaired surgically.

Unfortunately, the patient eventually died 5 months after aspiration of the barium from sepsis related to postoperative complications from several operations to relieve intestinal obstruction caused by adhesions from previous surgeries.

Acknowledgements The authors thanks Dr. Rajkumar Rajendram for his valuable contribution in manuscript writing.
Contributors MMA: data collection, manuscript writing and submission. MAA: data collection and image preparation. HA-J: treating physician, supervisor, manuscript reviewer and final approval for submission.

Competing interests None declared.

Patient consent Obtained.

Provenance and peer review Not commissioned; externally peer reviewed.

(c) BMJ Publishing Group Ltd (unless otherwise stated in the text of the article) . All rights reserved. No commercial use is permitted unless otherwise expressly granted.

\section{REFERENCE}

1 Doig AT. Baritosis: a benign pneumoconiosis. Thorax 1976;31:30-9.

Copyright 2017 BMJ Publishing Group. All rights reserved. For permission to reuse any of this content visit http://group.bmj.com/group/rights-licensing/permissions.

BMJ Case Report Fellows may re-use this article for personal use and teaching without any further permission.

Become a Fellow of BMJ Case Reports today and you can:

- Submit as many cases as you like

- Enjoy fast sympathetic peer review and rapid publication of accepted articles

- Access all the published articles

Re-use any of the published material for personal use and teaching without further permission

For information on Institutional Fellowships contact consortiasales@bmjgroup.com

Visit casereports.bmj.com for more articles like this and to become a Fellow 